\title{
Visual Outcome in Open Globe Injury.
}

Sagar Rajkarnikar ${ }^{1}$, Ramesh Raj Bist ${ }^{1}$, Anu Gurung ${ }^{1}$, Ram Shrestha ${ }^{1}$.

${ }^{1}$ Department of Ophthalmology, Shree Birendra Hospital.

\begin{abstract}
Introduction: Ocular trauma is a major cause of monocular blindness and visual impairment throughout the world. It is estimated that more than 2 million people suffer from ocular trauma annually and 40,000 become visually handicapped permanently. The aim of this study was to evaluate the visual outcome in open globe injury patients.

Methods: This study was conducted in Nepal Eye Hospital. All the cases of admitted open globe injuries were examined and managed in the hospital were included in this study. The detail history of trauma and visual acuity was recorded. Clinical diagnosis was made after detail examination of anterior and posterior segment. Patient was treated according to the type of injury. Visual recovery and the cause of poor vision at the time of discharge was also noted. Data was analyzed using the SPSS 11 program. Results: Out of the 100 cases enrolled in the study work related injury was the most frequent injury, metal was the most common causative agent. Males of 20-50 years of age are more vulnerable to open globe injury. Vision improved in $48 \%$, same vision in $39 \%$ and deteriorated vision in 13\% cases was recorded. Conclusions: Present study reveals that open globe injury can present in varying severity and though the overall prognosis is grave, prompt surgical intervention can result in better visual outcome. The visual outcome in mild to moderate ocular injury was satisfactory but poor in severe injuries.
\end{abstract}

Keywords: open globe injury, penetrating injury, rupture of globe.

\section{INTRODUCTION}

The exact number of ocular trauma in Nepal is not known. However, national survey conducted by HMG, WHO/PBL in 1981 has shown blindness due to ocular trauma is $2.4 \%^{1}$. Nepal blindness survey (1981) estimated that 8.6 persons per thousand gave history of trauma of which $27 \%$ were unilaterally blind and 3\% were bilaterally blind ${ }^{2}$. This national population based survey of blindness in Nepal (1981) found a blindness prevalence rate of $0.84 \%$, with trauma responsible for $7.9 \%$ of monocular blindness ${ }^{3}$.

Open globe injury is injury of the eye wall (corneoscleral) is a full- thickness wound. The open globe injury can be classified into different types: rupture, penetrating, intraorbital foreign bodies, perforating and mixed ${ }^{4}$.

During the last several decades, the prognosis for patients with ocular injuries, especially those with open-globe injuries, has significantly improved. This has been attributed to the advent of enhanced microsurgical techniques and instrumentation, along with an improved understanding of pathophysiologic mechanisms of ocular trauma ${ }^{5,6}$. The
Aim of this study was to evaluate the visual outcome in open globe injury cases and also to estimate the incidence, mode of injury and various traumatic agents of open globe injury admitted in Nepal Eye Hospital (NEH).

\section{METHODS}

This prospective interventional study was carried out for a period of $1 \frac{1}{2}$ year (from $1^{\text {st }}$ of Jan 2006 to $30^{\text {th }}$ June 2007) in Nepal Eye Hospital. All the cases of admitted open globe injuries were examined and managed at hospital were included in this study. The patients with close globe injuries and other non-mechanical injuries like chemical injuries; superficial corneal foreign bodies etc were excluded from the study.

Detailed history included, demographic profile (name, age, sex, address, and occupation of patient); nature and mode of trauma, causative agent; duration between trauma and primary intervention. Visual acuity was recorded with internally illuminated standard Snellen's chart or E-chart or by making them count fingers whichever was

\section{Correspondence:}

Dr Sagar Rajkarnikar

Department of Ophthalmology, Shree Birendra Hospital

Kathmandu, Nepal

E mail: sagarraj111@yahoo.com,

Mobile No.: +977-9841260116 
possible. Naked eye examination: To determine extent of injury, orbital margins, Light pupillary reflex, Direct and consensual on both sides, swinging flash light test to note presence or absence of relative afferent pupillary defect (RAPD). Detail anterior segment examination was performed on all patients using the slit lamp for the site, extent and type of lesion. Intraocular pressure of both eyes was measured digitally. Evaluation of the fundus was done under full mydriasis by using Direct Ophthalmoscope/90D or 78D/ Indirect Ophthalmoscope to see the condition of retina and optic nerve head, if the anterior segment lesion was not precluded such examination. X-ray orbit/skull (in different views) was done on routine basis. Ultrasonography of the orbit (B-scan) was done in patients when posterior segment evaluation could not be done clinically and also cases suspected with intraocular foreign bodies. Special investigations like CT scan and MRI of orbit and skull was done in cases whenever it was indicated. Once a clinical diagnosis was made, patient was put on supportive medical treatment and surgical treatment, which depend upon the type of injury. Visual recovery at the time of discharge was recorded. Cause of poor visual recovery at the time of discharge also was noted. Patient's demographic profile and clinical examination results was entered in the specially designed proforma and then in the computer. Data was analyzed using the SPSS 11.5.

\section{RESULTS}

The total numbers of cases included in this study were 100 eyes of 98 patients. All cases of open globe injuries in the age group 2-72 years were admitted in Nepal Eye Hospital. The incidence of ocular trauma in Nepal Eye Hospital in one year was $1.9 \%$.

Table: 1. distribution of patients by their age and sex group

\begin{tabular}{|c|c|c|c|c|c|c|}
\hline \multirow[t]{2}{*}{ Age } & \multicolumn{2}{|c|}{ Male } & \multicolumn{2}{|c|}{ Female } & \multicolumn{2}{|c|}{ Total } \\
\hline & $\mathbf{N}$ & $\%$ & $\mathbf{N}$ & $\%$ & $\mathbf{N}$ & $\%$ \\
\hline$<10$ & 8 & $11.1 \%$ & 5 & $17.9 \%$ & 13 & $13.0 \%$ \\
\hline 10-19 & 12 & $16.7 \%$ & 7 & $25.0 \%$ & 19 & $19.0 \%$ \\
\hline $20-29$ & 20 & $27.8 \%$ & 1 & $3.6 \%$ & 21 & $21.0 \%$ \\
\hline 30-39 & 8 & $11.1 \%$ & 2 & $7.1 \%$ & 10 & $10.0 \%$ \\
\hline $40-49$ & 12 & $16.7 \%$ & 6 & $21.4 \%$ & 18 & $18.0 \%$ \\
\hline 50-59 & 6 & $8.3 \%$ & 3 & $10.7 \%$ & 9 & $9.0 \%$ \\
\hline 60-69 & 4 & $5.6 \%$ & 2 & $7.1 \%$ & 6 & $6.0 \%$ \\
\hline$>70$ & 2 & $2.8 \%$ & 2 & $7.1 \%$ & 4 & $4.0 \%$ \\
\hline Total & 72 & $100.0 \%$ & 28 & $100.0 \%$ & 100 & $100.0 \%$ \\
\hline
\end{tabular}

The male: female ratio was $3: 1$. Among them the youngest age was 2 years and oldest of 72 years. Injury in men on right eye $47.2 \%$, left eye $52.7 \%$ whereas in women on right and left eye accounted 50\%.

Regarding the mode of trauma, maximum numbers of injury related to profession, accounted $32 \%$ eyes followed by injury related to domestic work (18\%), sport (13\%) fall down (12\%), physical assault (4\%), RTA (2\%) and unspecified injury accounted $19 \%$.

\section{Table 2. Causative agent of open globe injury}

\begin{tabular}{|lll|}
\hline Causative Agent & Number & Percent \\
\hline Wooden piece & 18 & 18.0 \\
\hline Metallic & 37 & 37.0 \\
\hline Stone & 19 & 19.0 \\
\hline Glass & 6 & 6.0 \\
\hline Plastic & 2 & 2.0 \\
\hline Miscellaneous & 17 & 17.0 \\
\hline Unknown & 1 & 1.0 \\
\hline Total & 100 & 100.0 \\
\hline
\end{tabular}

The most common causative agent was metal which accounted $37 \%$. In miscellaneous group accounted $17 \%$ of injury, which included horn of cattle, beak of hen, edge of cemented wall, finger of children, fist, maize stem, nylon rope, zipper of clothes, playing marble etc.

The most common place for injury was work places (32\%) followed by home, play ground, road, field and in 1 case patient was alcoholic, and he did not know where and how the incident happened.

Table 3. Unaided visual acuity

\begin{tabular}{|lllll|}
\hline \multicolumn{1}{|c}{ Visual Acuty } & \multicolumn{2}{c}{ at presentation } & \multicolumn{2}{c|}{ on discharge } \\
& Frequency & \% & Frequency & $\%$ \\
\hline NPL & 17 & 17.0 & 16 & 16.0 \\
\hline PL+PR(inaccurate) & 26 & 26.0 & 15 & 15.0 \\
\hline PL+PR(accurate) & 21 & 21.0 & 12 & 12.0 \\
\hline HM close to face & 5 & 5.0 & 13 & 13.0 \\
\hline Finger count close to face & 5 & 5.0 & 9 & 9.0 \\
1/60-3/60 & 12 & 12.0 & 6 & 6.0 \\
\hline 4/60-6/60 & 2 & 2.0 & 7 & 7.0 \\
6/36-6/18 & 8 & 8.0 & 18 & 18.0 \\
6/12-6/9 & 4 & 4.0 & 3 & 3.0 \\
6/6 & 0 & 0.0 & 1 & 1.0 \\
\hline
\end{tabular}

NPL: No Perception of Light; PL: Perception of Light; PR: Projection of Rays; HM: Hand Movement

According to WHO definition of blindness, $86 \%$ eyes were blind at the time of presentation. Results of examination of an RAPD were recorded at the time of admission in $92 / 100$ (92\%). In 72/92 (78.2\%), an RAPD was absent, but present in the remaining $20 / 92(21.7 \%)$. 
Table 4. Cause of poor visual outcome

\begin{tabular}{|lll|}
\hline Causes & Frequency & Percent \\
\hline Anterior segment cause & 59 & 60.20 \\
Posterior segment cause & 8 & 8.16 \\
Anterior + Posterior segment cause & 16 & 16.32 \\
Others & 15 & 15.30 \\
Total & 98 & 100.0 \\
\hline
\end{tabular}

The causes for poor vision at the time of discharge included $60.20 \%$ cases of only anterior segment cause, similarly that of only posterior segment accounted $8.16 \%$ cases. $16.32 \%$ cases had poor vision due to anterior and posterior segment cause and due to others cause for poor vision in $15.30 \%$ cases.

Among the types of injuries, better visual outcome in penetration type of injury in compare to initial vision, whereas the almost same vision in case of IOFB type of mode of injury.

\section{DISCUSSION}

Ocular trauma is now regarded as a major cause of visual morbidity, around the world half a million blinding eye injuries occur every year, there are approximately 1.6 million people blind from eye injuries, 2.3 million bilaterally visually impaired and 19 million with unilateral visual loss; this being the commonest cause of unilateral blindness today. Maximum incidence is found in young adults and elderly ${ }^{7,8}$ and is much more common in males ${ }^{9,10}$.

In this study the most commonly affected age group due to trauma was between $20-29$ years (21\%) and least ( $4 \%$ eyes) in $>70$ years (Table 1). This comprises the economically productive age group and visual morbidity due to trauma in this age group results in great deal of economic loss. Male preponderance is seen in ocular trauma ${ }^{9-16}$. In the present study also, $72 \%$ were males. The male predominance of injuries may be a result of being engaged in different activities with different degree of risk of ocular injury ${ }^{17}$.

In our study the involvement of both the eyes were almost similar in contrast to similar studies where right eye is injured more frequently than the left eye 7, 9, 13, 14, 16, 18-20. Our study injury related to profession, accounted 32\%, followed by related to domestic work (18\%), sport related injury (13\%), fall (12\%). profession related to frequent eye injury included stone hammering (12\%), nails hammering (9\%) and rest $11 \%$ cases related to other industrial works.
Unspecified group (19\% cases) include injury while feeding cattle, pecked by hen while playing, taking out nail from wall, taking off the mosquito net, knotting the nylon rope, bunch of key passed by friend, finger of children, while zippering the clothes, blast while firing on wedding ceremony, while looking out of window and alcohol consumption.

The most frequent causative agent was metal which accounted 37 cases, then stone and wooden piece were almost equal in numbers i.e. 19 and 18 respectively. Lam SR et $\mathrm{al}^{14}$ found that the injury to the eye with a sharp object accounted for $66 \%$ cases and blunt mechanisms for $28 \%$ cases in their series. They found that the injury by sharp object was among the most common mechanism of injury. All the patient underwent surgical repair initially. After appropriate surgery in $48 \%$ had improved vision on discharge, $39 \%$ had same vision and vision deteriorated in $13 \%$ at the time of discharge(Table 3 ).

Prognostic factors for visual outcome include presenting visual acuity, relative afferent pupillary defect, wound location, lens injury, retinal detachment and endophthalmitis $^{21}$. Cataract was the most common anterior segment cause of poor vision at the time of discharge (32\%), followed by corneal opacity/ scar/FB (19\%), hyphema (13\%), anterior chamber reaction (11\%) and aphakia in $13 \%$ cases. The posterior segment causes of poor vision included vitreous hemorrhage $15 \%$, retinal detachment accounted 5\% and followed by other posterior segment lesions like PVR, choroidal detachment, Berlin's edema, macular edema, retinal fold etc accounted about $10 \%$. In indicator of poor prognosis identified in our study were similar to those identified by other studies, comprising length of wound $>11 \mathrm{~mm}$, mixed corneoscleral would location, and involvement of the lens and posterior segment.

\section{CONCLUSIONS}

Work related injury (32\%) was the most common mode for open globe injury. Open globe injury can present in varying severity and though the overall prognosis is grave, prompt surgical intervention can result in better visual outcome. The visual outcome in mild to moderate ocular injury was satisfactory but in severe injuries, it was poor despite of all possible treatment available in our center.

\section{REFERENCES}

1. National Survey conducted by WHO/PBL, 1981.

2. The Epidemiology of blindness in Nepal. A report of the $1981 \mathrm{Nepal}$ Blindness Survey, the Seva Foundation. Chelsea, 1988 
3. Upadhyay MP, Karmacharya PC, Koirala S, Shah DN, Shakya S, Shrestha JK, Bajracharya H, Gurung CK, Whitcher JP. The Bhaktapur eye study: ocular trauma and antibiotic prophylaxis for the prevention of corneal ulceration in Nepal Br J Ophthalmol 2001;85:388-92.

4. Pieramici DJ, Sternberg P, Aaberg TM Sr, et al. A system for classifying mechanical injuries of the eye (globe). Am J Ophthalmol. 1997;123(6):82031.

5. Albert \& Jakobiec Azar Gragoudas. Principle and Practice in Ophthalmology; 2nd Edition; W.B. Saunders Company 2000: Vol VI: p5177-322.

6. Adhikari R.K. Traumatic Corneal Lesions in King Mahendra Memorial Eye Hospital, Chitwan. Kathmandu University Medical Journal 2006; Vol 4, No 1, Issue 13: 34-9.

7. Sternberg PJ, de Duan E Jr. Penetrating Injuries and visual results; Retina. 1984;4(1):5-8.

8. Glynn RJ, Seddon JM, Berlin BM. The incidence of eye injuries in New England. Arch Ophthalmol. 1988;106 (6):785-9.

9. Smith D, Wrenn K, Stack LB. The epidemiology and diagnosis of penetrating eye injuries. Acad Emerg Med .2002 Mar; 9 (3): 209-13.

10. Thylefors B. Epidemiological patterns of ocular trauma. Aust N Z J Ophthalmol. 1992;20(2):95-8.

11. Lubeck D. Penetrating ocular injuries. Emerg Med Clin North Am. 1988;6(1):127-46.

12. Pieramici DJ, Au Eong KG, Sternberg P Jr, Marsh MJ. The prognostic significance of a system for classifying mechanical injuries of the eye (globe) in open-globe injuries. J Trauma. 2003;54(4):750-4.

13. Grieshaber MC, Stegmann R. Penetrating eye injuries in South African children: aetiology and visual outcome. Eye. 2006;20(7):789-95.

14. Lam SR, Devenyi RG, Berger AR, Dunn W. Visual outcome following penetrating globe injuries with retained intraocular foreign bodies. Can J Ophthalmol. 1999;34(7):389-93.

15. Vasu U, Vasnaik A, Battu RR, Kurian M, George S. Occupational open globe injuries: Indian J Ophthalmol. 2001;49(1):43-7.

16. Parver LM, Dannenberg AL, Blacklow B, Fowler CJ, Brechner RJ, Tielsch JM. Characteristics and causes of penetrating eye injuries reported to the National Eye Trauma System Registry, 1985-91.

17. Rostomian K, Thach AB, Isfahani A et al. Open globe injuries in children. J AAPOS. 1998;2(4):234-8.

18. Wykes WN. A 10-year survey of penetrating eye injuries in Gwent, 1976-85. Br J Ophthalmol. 1988;72(8):607-11.

19. Sapkota YD, Pokharel GP, Nirmalan PK, Dulal S, Maharjan IM, Kayastha P. Prevalence of blindness and cataract surgery in Gandaki Zone, Nepal. Br J Ophthalmol 2006; 90: 411-6.

20. Khatry SK, Lewis AE, Schein OD, Thapa MD, Pradhan EK, Katz J. The epidemiology of ocular trauma in rural Nepal. Br J Ophthalmol. 2003;88(4):456-9.

21. Hooi SH. Hooi ST. Open-globe injuries: the experience at Hospital Sultanah Aminah, Johor Bahru. Med J Malaysia. 2003;58(3):405-12. 